\title{
Perilaku Cuci Tangan Pakai Sabun pada Santri di Pondok Pesantren Kota Medan
}

\author{
Tri Bayu Purnama ${ }^{1}$, Sri Rezeki Hartati Eliandy ${ }^{1}$, Cindy Lestari ${ }^{1}$ \\ ${ }^{1}$ Fakultas Kesehatan Masyarakat Universitas Islam Negeri Sumatera Utara
}

\section{ABSTRACT}

Background: Islamic Boarding School is one of the domains of education to introduce the PHBS Program. One of the indicators is washing hands with soap. It is expected that the pesantren community could apply the indicators of PHBS Program and protected from various diseases. This study aimed to describe the practice of washing hands with soap among santri at Islamic Boarding Schools In Medan.

Method: This research was a quantitative study using Cross-Sectional design. The sampling technique was using Simple Random Sampling. The population was all students in seven Islamic boarding school in Medan. The samples were 436 santri (students). Data was collected using a questionnaire and analyzed using the ChiSquare test.

Result: The age of students who washed their hands with soap had an insignificant difference in proportions, in which the p-value was $0.204>0.005$ with Prevalens Risk (PR) on 95\% CI 1.331 (0.855 - 2.071). The sex of students who washed their hands with soap had a p-value of $0.137>0.005$ with PR on 95\% CI 0.725 (0.4751.108), which means there was no significant difference in the proportion. The education level also did not have a significant difference with the behavior of washing hands with soap with a p-value of $0.210>0.005$ with PR on 95\% CI 1.375 $(0.835-2.266)$. The practice of washing hands with soap among santri was poor. The highest percentage of washing hands with soap among santri was in the boarding school with a percentage of $47.9 \%$. There was no significant difference in the proportion of age, sex, and education level with the practice of handwashing with soap among santri.

\section{Correspondence \\ tribayupurnama@uinsu.ac.id}

\section{Article History}

Received 2 February 2020

Revised 2 April 2020

Accepted 20 April 2020

Available Online 12 June 2020

Keywords

Behavior

Hand wash

Students

Islamic boarding school

\section{DOI}

10.14710./jpki.15.2.70-74

\section{PENDAHULUAN}

Pesantren adalah institusi pendidikan tertua di Indonesia dengan jumlah 27.123 pesantren dan 3.666.467 santri yang tersebar di seluruh wilayah Indonesia. ${ }^{1}$ UndangUndang Pesantren No 18 Tahun 2019 menjelaskan bahwa peranan Pesantren tidak hanya berfokus pada pengembangan karakter dan pendidikan Islam pada santri tapi juga mempertimbangkan aspek kesehatan dalam menunjang kegiatan pembelajaran di Pesantren. Pesantren sebagai kelompok rentan terhadap masalah kesehatan sehingga upaya program perilaku hidup bersih dan sehat menjadi bagian dalam program pengembangan pesantren berwawasan kesehatan berkelanjutan.

Perilaku hidup bersih dan sehat dengan indikator Cuci Tangan Pakai Sabun (CTPS) bertujuan untuk melindungi santri, santriwati, ustadz, ustadzah dan masyarakat lingkungan pesantren dari berbagai gangguan dan ancaman penyakit. $^{2}$ Riset Kesehatan Dasar (RISKESDAS) menunjukkan secara nasional masih rendahnya perilaku cuci tangan pakai sabun sebesar $49,8 \%$ pada penduduk umur $>10$ tahun. ${ }^{3}$ Berdasarkan studi pendahuluan yang dilakukan pada salah satu tempat makan santri pondok pesantren, didapati 7 dari 10 santri tidak mencuci tangan sebelum makan, dan 3 orang yang mencuci tangan hanya menggunakan air tanpa sabun padahal telah disediakan wastafel, dengan sabun, air mengalir dan handuk.

World Health Organization mengemukakan bahwa mencuci tangan pakai sabun dapat mengurangi angka infeksi saluran pernafasan hingga $25 \%$ dan menurunkan angka penderita diare hingga 44\%. ${ }^{4}$ Menurut Infodatin, penyakitpenyakit yang dapat dicegah dengan mencuci tangan pakai sabun adalah infeksi saluran pernapasan, diare, pneumonia, infeksi cacing, infeksi mata, dan penyakit kulit. Berdasarkan Kementerian Kesehatan RI ada beberapa penyakit yang dapat dicegah dengan cuci tangan yang benar, seperti penyakit diare, penyakit pernafasan, hepatitis, tipus, dan flu burung. 
Pondok pesantren identik dengan kehidupan yang sederhana dan sarana dan prasarana yang terbatas. ${ }^{5}$ Hal tersebut menjadikan pengetahuan santri tentang kesehatan terbatas dan perilaku mencuci tangan masih belum menjadi kebiasaan. Sedangkan mencuci tangan pakai sabun merupakan upaya preventif dalam melindungi diri dari berbagai penyakit menular. Oleh karena itu, penelitian ini bertujuan untuk mengetahui gambaran perilaku CTPS pada santri di 7 Pondok Pesantren Kota Medan.

\section{METODE}

Desain penelitian menggunakan desain crosssectional yang bertujuan untuk mengetahui gambaran masalah kesehatan di Pondok Pesantren Kota Medan. Jumlah pesantren yang terdaftar dalam database sistem pesantren nasional Kementerian Agama tahun 2019 berjumlah 9 pesantren dan 7 pesantren dijadikan sampel pada penelitian ini. Penelitian ini telah dilakukan pada bulan Oktober-November 2019 di 7 Pesantren Kota Medan. Pada penelitian ini pengambilan sampel pada populasi menggunakan teknik pengambilan sampel yaitu simple random sampling. Metode penarikan sampel acak sederhana adalah suatu prosedur yang memungkinkan setiap elemen dalam populasi akan memiliki peluang yang sama untuk dijadikan sampel. ${ }^{6}$ Probability proportional of size digunakan untuk menghitung jumlah sampel yang dibutuhkan pada masing-masing pesantren dikarenakan jumlah santri pada masing-masing pondok pesantren berbeda cukup signifikan.

Populasi penelitian ini adalah seluruh Santri dan Santriwati yang tersebar di Kota Medan Provinsi Sumatera Utara Tahun 2019. Sampel yang digunakan dalam penelitian ini berasal dari 7 pesantren yang ada di Kota Medan dengan rumus survey deskriptif kategorik, yakni: $n=\mathrm{Z} \alpha^{2} p(1-p) \mathrm{d}$. Tingkat kemaknaan yang digunakan adalah kesalahan alpha $5 \%$ yaitu 1,96 dan presisi (d) yang digunakan adalah $5 \%$. Adapun estimasi proporsi yang digunakan adalah proporsi tertinggi oleh penelitian. ${ }^{7}$ Maka berdasarkan rumus diatas didapatkan sampel 436 orang yang telah ditambahkan 10\% dalam sampling. Penggunaan drop out dimaksudkan untuk mengantisipasi apabila terdapat data sampel yang tidak sesuai atau yang tidak terisi yang menyebabkan data sampel tersebut dikeluarkan.

Instrumen pengumpulan data dalam penelitian ini adalah self-report questionnaire dimana sampel mengisi sendiri kuesioner yang diberikan oleh enumerator yang telah dilatih sebelum pengumpulan data dilakukan. Cuci tangan pakai sabun didefinisikan sebagai kegiatan mencuci tangan pada aktivitas sebelum atau makan, tangan keadaan kotor dan setelah buang air kecil atau setelah buang air besar dengan menggunakan sabun dalam 6 bulan terakhir. Karakteristik demografi santri juga diukur dalam penelitian ini untuk mengetahui sebaran karakteristik santri yang mencuci tangan dengan menggunakan sabun.

Analisis data yang digunakan pada penelitian ini adalah proporsi cuci tangan pakai sabun pada karakteristik santri. Uji chi square digunakan untuk mengetahui signifikansi perbedaan proporsi pada masing-masing kelompok variable yang diteliti. Penelitian ini telah mendapatkan persetujuan etik penelitian dari Komite Etik Fakultas Kedokteran Universitas Islam Sumatera Utara.

\section{HASIL DAN PEMBAHASAN}

Berdasarkan hasil penelitian dapat dilihat bahwa dari 436 responden, sebanyak 267 responden $(61,2 \%)$ berusia $10-13$ tahun dan 169 responden $(38,8 \%)$ berusia $14-$ 17 tahun. Sebanyak 225 responden (51,6\%) berjenis kelamin laki laki dan 211 responden $(48,4 \%)$ berjenis kelamin perempuan. Sebanyak 321 responden $(73,6 \%)$ berada pada tingkat pendidikan SMP dan 115 responden $(26,4 \%)$ berada pada tingkat pendidikan SMA.

Dari tabel 1 dapat diketahui bahwa usia pada santri yang tertinggi adalah usia 10-13 tahun yaitu sebanyak $267(61,2 \%)$. Santri dengan jenis kelamin terbanyak yaitu laki-laki $225(51,6 \%)$, dan tingkat pendidikan terbanyak pada santri adalah SMP yang berjumlah $321(73,6 \%)$.

Tabel 2 menunjukkan perilaku CTPS yang dilakukan oleh santri berdasarkan tempat pondok pesantren yang paling baik yaitu pondok pesantren AK dengan presentase santri yang melakukan cuci tangan pakai sabun adalah $47,9 \%$ atau sebanyak 35 santri dari 73 total santri. Sedangkan presentase terendah terdapat pada santri di pondok pesantren IC yaitu sebesar $12,5 \%$ atau sebanyak 8 santri dari 64 santri.

Tabel 1. Distribusi karakteristik santri

\begin{tabular}{lcc}
\hline Variabel Kategori & \multicolumn{2}{c}{ Jumlah } \\
\cline { 2 - 3 } & $\mathrm{n}$ & $\%$ \\
\hline Usia & 267 & 61,2 \\
$\quad 10-13$ & & \\
$\quad 14-17$ & 169 & 38,8 \\
$\quad$ Jenis kelamin & & \\
$\quad$ Laki-laki & 225 & 51,6 \\
$\quad$ Perempuan & 211 & 48,4 \\
Tingkat pendidikan & 321 & 73,6 \\
$\quad$ SMP & & \\
$\quad$ SMA & 115 & 26,4 \\
\hline
\end{tabular}


Tabel 2. Distribusi perilaku CTPS di 7 pondok pesantren di Kota Medan tahun 2019

\begin{tabular}{|c|c|c|c|c|c|c|}
\hline \multirow[t]{3}{*}{ Pondok Pesantren } & \multicolumn{4}{|c|}{ CTPS } & \multicolumn{2}{|c|}{ Total } \\
\hline & \multicolumn{2}{|c|}{ Iya } & \multicolumn{2}{|c|}{ Tidak } & \multirow[b]{2}{*}{$\mathrm{n}$} & \multirow[b]{2}{*}{$\%$} \\
\hline & $\mathrm{n}$ & $\%$ & $\mathrm{n}$ & $\%$ & & \\
\hline Pesantren $\mathrm{AH}$ & 49 & 23,9 & 156 & 76,1 & 205 & 100 \\
\hline Pesantren IC & 8 & 12,5 & 56 & 87,5 & 64 & 100 \\
\hline Pesantren AK & 35 & 47,9 & 38 & 52,1 & 73 & 100 \\
\hline Pesantren H & 9 & 32,1 & 19 & 67,9 & 28 & 100 \\
\hline Pesantren DH & 5 & 13,9 & 31 & 86,1 & 36 & 100 \\
\hline Pesantren US & 3 & 30,0 & 7 & 70,0 & 10 & 100 \\
\hline Pesantren TS & 9 & 45,0 & 11 & 55,0 & 28 & 100 \\
\hline
\end{tabular}

Tabel 3. Distribusi perilaku CTPS santri

\begin{tabular}{|c|c|c|c|c|c|c|c|c|}
\hline \multirow[t]{3}{*}{ Variabel } & \multicolumn{4}{|c|}{ CTPS } & \multirow{2}{*}{\multicolumn{2}{|c|}{ Total }} & \multirow[t]{3}{*}{ P value } & \multirow{3}{*}{$\begin{array}{c}\text { PR } \\
(95 \% \mathrm{CI})\end{array}$} \\
\hline & \multicolumn{2}{|c|}{ Iya } & \multicolumn{2}{|c|}{ Tidak } & & & & \\
\hline & $\mathrm{n}$ & $\%$ & $\mathrm{n}$ & $\%$ & $\mathrm{n}$ & $\%$ & & \\
\hline \multicolumn{9}{|l|}{ Usia } \\
\hline 10-13 Tahun & 78 & 29,2 & 189 & 70,8 & 267 & 100 & \multirow[t]{2}{*}{0,204} & 1.331 \\
\hline 14-17 Tahun & 40 & 23,7 & 129 & 76,3 & 169 & 100 & & $(0,855-2.071)$ \\
\hline \multicolumn{9}{|l|}{ Jenis Kelamin } \\
\hline Laki-laki & 54 & 24,0 & 171 & 76,0 & 225 & 100 & \multirow[t]{2}{*}{0,137} & 0,725 \\
\hline Perempuan & 64 & 30,3 & 147 & 69,7 & 211 & 100 & & $(0,475-1,108)$ \\
\hline \multicolumn{9}{|c|}{ Tingkat Pendidikan } \\
\hline SMP & 92 & 28,7 & 229 & 71,3 & 321 & 100 & \multirow[t]{2}{*}{0,210} & 1,375 \\
\hline SMA & 26 & 22,6 & 89 & 77,4 & 115 & 100 & & $(0,835-2,266)$ \\
\hline
\end{tabular}

Dari tabel 3 di atas dapat diketahui bahwa usia santri yang melakukan CTPS memiliki perbedaan proporsi yang tidak signifikan yaitu nilai $p$ value $0,204>0,005$ dengan nilai Prevalens Risk (PR) pada 95\% CI 1,331 (0,855 - 2,071). Perilaku santri yang melakukan CTPS tertinggi adalah usia 10-13 tahun yang berjumlah 78 (29,2\%) dari 267 santri. Jenis kelamin santri yang melakukan CTPS memiliki nilai $p$ value $0,137>0,005$ dengan nilai Prevalens Risk $(P R)$ pada $95 \%$ CI $0,725(0,475$ - 1,108) yang artinya tidak terdapat perbedaan proporsi yang signifikan. Perilaku CTPS yang dilakukan oleh santri berdasarkan jenis kelamin tertinggi adalah perempuan yaitu sebanyak 64 santri $(30,3 \%)$ dari 211 santri jika dibandingkan dengan jenis kelamin lakilaki yaitu 54 santri (24,0\%). Tingkat pendidikan santri di 7 Pondok Pesantren Kota Medan tidak memiliki perbedaan yang signifikan dengan perilaku Cuci Tangan Pakai Sabun dengan nilai $p$ value $0,210>0,005$ yang memiliki nilai Prevalens Risk (PR) pada 95\% CI 1,375 (0,835 - 2,266). Tingkat pendidikan santri yang tertinggi melakukan cuci tangan pakai sabun adalah tingkat pendidikan SMP yaitu sebesar $92(28,7 \%)$ dari 321 total santri.

Berdasarkan tabel distribusi karakteristik Santri/Santriwati dapat diketahui bahwa rentang usia 10-13 lebih banyak yaitu 267 orang $(61,2 \%)$ daripada rentang usia
14-17 yaitu 169 orang (38,8\%). Berdasarkan jenis kelamin diketahui jumlah santri/santriwati dengan rincian santri lakilaki sebanyak 225 orang $(51,6 \%)$ dan santriwati sebanyak $211(48,4 \%)$. Santri/Santriwati yang menjadi responden dalam penelitian ini memiliki tingkat pendidikan terbanyak pada Sekolah Menengah Pertama (SMP) sebanyak 321 orang (73,6\%) dan terendah pada Sekolah Menegah Atas (SMA) sebanyak 115 orang atau sebanyak $26,4 \%$.

Diketahui bahwa perilaku CTPS yang dilakukan oleh santri rata-rata masih rendah dan yang melakukan CTPS cukup tinggi yaitu pada santri yang berada di Pondok Pesantren AK dibandingkan 6 pondok pesantren lainnya yaitu sebanyak 35 santri (47,9\%) dari 73 santri yang dijadikan sebagai sampel penelitian. Hal ini sesuai dengan penelitian sebelumnya yang mengatakan bahwa sebanyak 156 santri $(60,5 \%)$ memiliki perilaku yang baik dalam melakukan cuci tangan dan hasil penelitian menyebutkan bahwa santri yang melakukan perilaku cuci tangan tersering adalah setelah buang besar atau kecil. ${ }^{8}$ Sedangkan presentase CTPS yang dilakukan oleh santri di Pondok Pesantren IC merupakan yang terendah yaitu 8 santri $(12,5 \%)$ dari total 64 total santri yang dijadikan sampel penelitian. Hal ini sesuai dengan penelitian yang dilakukan oleh Alda yang mengatakan bahwa kebiasaan mencuci tangan menggunakan sabun pada santri 
masih rendah yaitu $77,5 \%$ responden tidak memiliki kebiasaan mencuci tangan dengan sabun sebelum makan. ${ }^{9}$

Usia santri yang melakukan CTPS memiliki perbedaan proporsi yang tidak signifikan yaitu nilai $p$ value 0,204 > 0,005 dengan nilai Prevalens Risk (PR) pada 95\% CI $1,331(0,855-2,071)$. Perilaku santri yang melakukan CTPS tertinggi adalah usia 10-13 tahun yang berjumlah 78 $(29,2 \%)$ dari 267 santri. Hal ini sejalan dengan penelitian yang dilakukan oleh yang mengatakan bahwa perilaku responden yang melakukan kebersihan diri kurang lebih banyak ditemukan pada kelompok santri yang berusia 16-18 tahun yaitu $61,7 \%$ dibandingkan dengan kelompok santri yang berusia $13-15$ tahun yaitu $54,2 \% .^{10}$ Adanya perubahan tidak akan berdampak pada terjadinya perubahan perilaku. Hasil penelitian ini menunjukkan bahwa tidak ada hubungan yang signifikan antara umur responden dengan perilaku kebersihan diri pada santri di pondok pesantren Kabupaten Brebes dengan hasil uji Chi Square didapatkan $p$ value yaitu 0,232 . Sehingga dalam penelitian ini (faktor internal) untuk berperilaku positif pada santri khususnya faktor umur santri tidak terbukti. Usia remaja memiliki jarak akan tetapi setiap responden mempunyai pola pikir yang hampir sama, sehingga usia tidak dapat menjadi pengaruh dari tingkat pengetahuan dan sikap responden dalam berperilaku.

Jenis kelamin santri yang melakukan CTPS memiliki nilai $p$ value $0,137>0,005$ dengan nilai Prevalens Risk (PR) pada 95\% CI 0,725 $(0,475-1,108)$ yang artinya tidak terdapat perbedaan proporsi yang signifikan. Perilaku CTPS yang dilakukan oleh santri berdasarkan jenis kelamin tertinggi adalah perempuan yaitu sebanyak 64 santri (30,3\%) dari 211 santri jika dibandingkan dengan jenis kelamin lakilaki yaitu 54 santri (24,0\%). Penelitian ini sejalan dengan penelitian yang dilakukan oleh yang menjelaskan tentang perbedaan jenis kelamin tidak memiliki pengaruh yang signifikan melainkan tingkat pendidikan seseorang yang sangat berpengaruh terhadap program peningkatan pengetahuan secara lansung maupun tidak langsung dalam mengubah suatu perilaku seseorang. ${ }^{11}$ Penelitian lain yang mendukung adalah penelitian yang menggunakan penelitian kuantitatif yang berupa study survey yang bersifat korelasi dengan pendekatan cross sectional terhadap 63 responden dengan kesimpulan bahwa tidak ada perbedaan yang signifikan tentang pengetahuan perilaku hidup bersih dan sehat antara santri putra dan santri putri. ${ }^{12}$

Tingkat pendidikan santri di 7 Pondok Pesantren Kota Medan tidak memiliki perbedaan yang signifikan dengan perilaku Cuci Tangan Pakai Sabun dengan nilai $p$ value $0,210>0,005$ yang memiliki nilai Prevalens Risk (PR) pada $95 \%$ CI $1,375(0,835-2,266)$. Tingkat pendidikan santri yang tertinggi melakukan cuci tangan pakai sabun adalah tingkat pendidikan SMP yaitu sebesar $92(28,7 \%)$ dari 321 total santri. Sedangkan tingkat pendidikan SMA lebih rendah yaitu 26 santri $(22,6 \%)$ dari 115 total santri. Hal ini tidak sejalan dengan pernyataan Notoatmodjo, respon seseorang terhadap suatu hal dipengaruhi oleh tingkat pendidikan. ${ }^{13}$ Pada individu dengan pendidikan tinggi akan memberikan respon yang logis terhadap informasi yang datang dan akan berpikir sejauh mana pengaruh yang diperoleh. Mubarak mengungkapkan bahwa tidak dapat dipungkiri bahwa semakin mudah seseorang memahami informasi dipengaruhi oleh tingkat pendidikan serta semakin bertambah pula informasi yang diketahui dan sebaliknya. ${ }^{14}$

Berdasarkan hasil penelitian diketahui bahwa rendahnya perilaku cuci tangan pakai sabun pada santri ratarata disebabkan karena tidak terbiasa menggunakan sabun ketika cuci tangan, terburu-buru, malas, dan lain sebagainya. Perilaku ini dapat terjadi akibat beberapa faktor yang dapat mempengaruhi terbentuknya suatu perilaku yaitu niat dan keinginan, motivasi, dan juga faktor lingkungan termasuk kebiasaan teman atau orang-orang disekitar yang dapat berpengaruh pada perilaku individu. Salah satu cara sederhana perilaku hidup bersih dan sehat adalah dengan melakukan cuci tangan pakai sabun untuk meningkatkan kesadaran tentang pemeliharaan kesehatan pribadi. Namun cuci tangan pakai sabun sering dianggap sebagai hal yang sepele di masyarakat tidak terkecuali pada santri yang tinggal dan menetap di Pondok Pesantren. Berdasarkan fenomena yang terjadi, banyak anak-anak usia sekolah mempunyai kebiasaan kurangnya memperhatikan perlunya cuci tangan dalam kehidupan sehari-hari. Santri biasanya langsung makan makanan yang disajikan tanpa mencuci tangan pakai sabun terlebih dahulu. Perilaku tersebut tentunya berpengaruh dan dapat memberikan kontribusi dalam terjadinya penularan penyakit. ${ }^{15}$

Kebiasaan CTPS di Pondok Pesantren dapat dipengaruhi dari lingkungan tempat Pondok Pesantren itu sendiri. Pondok Pesantren yang tidak menyediakan tempat untuk cuci tangan menggunakan sabun. Selain itu, faktor lain yang mendukung adalah kurangnya pengetahuan santri terkait pentingnya cuci tangan dan peran kebiasaan cuci tangan terhadap timbulnya penyakit. Selain faktor pengetahuan, pihak pengasuh atau pengurus pondok pesantren perlu memperhatikan perilaku kebersihan diri para santri dengan dengan membiasakan melakukan CTPS sebelum atau setelah makan, dan setelah BAB atau BAK. Perlunya memberikan peraturan yang ketat kepada para santri untuk menjaga kebersihan diri dan penerapan kebiasaan. ${ }^{16}$

\section{SIMPULAN}

Personal Hygiene pada santri masih memiliki perilaku CTPS yang rendah, Perilaku CTPS yang tertinggi terdapat di Pondok Pesantren AK dengan presentase $47,9 \%$. Tidak ada perbedaan proporsi yang signifikan antara variable usia, jenis kelamin, dan tingkat pendidikan dengan perilaku CTPS pada santri yang masing-masing variabel memiliki nilai $p$ value $>0,005$. 


\section{KEPUSTAKAAN}

1. Kementrian Agama RI. EMIS Dashboard [Internet]. Sekretariat Direktorat Jenderal Pendidikan Islam Kementrian Agama RI; 2019. Available from: https:/ditpdpontren.kemenag.go.id/web/

2. Departemen Kesehatan RI. Pedoman Program Perilaku Hidup Bersih dan Sehat. Jakarta: Departemen Kesehatan RI; 2010.

3. Riset Kesehatan Dasar. Badan Penelitian dan Pengembangan Kesehatan RI [Internet]. Jakarta; 2018. Available from: www.kesmas.kemkes.go.id

4. Global Handwashing Partnership. Fact sheet: Hand Hygiene in Healthcare Facilities [Internet]. August 2017. Available from: https://globalhandwashing.org/wpcontent/uploads/2017/08/GHP-Hygiene-in-HCFsFact-Sheet-Aug2017.pdf

5. Hidayat DAJ. Perbedaan Penyesuaian Diri Santri Pondok Pesantren Tradisional dan Modern [Internet]. Talenta Psikologi. 2012; 1(2):107-126

6. Dharma KK. Metodologi Penelitian Keperawatan. Jakarta: TIM; 2017

7. Hadi MI. Hubungan Perilaku Hidup Bersih dan Sehat (PHBS) Terhadap Angka Kejadian Diare Akut Pada Santri Pondok Tremas Kabupaten Pacitan [Internet]. Fakultas Kedokteran Universitas Muhammadiyah Surakarta. Universitas Muhammadiyah Surakarta; 2017. Available from: http://eprints.ums.ac.id/55841/

8. Syukri S. Gambaran Pengetahuan dan Perilaku Santri Mengenai Kebersihan Pribadi dan Tempat Tinggal Pada Pesantren X di Kabupaten Bogor [Internet]. UIN Jakarta; 2017. Available from: http://repository.uinjkt.ac.id

9. Alda EM, J Mukono. Hubungan Karakteristik Santri dan Kebiasaan Mencuci Tangan Dengan Kejadian Kecacingan di Pondok Pesantren Kabupaten Blitar. Jurnal Kesehatan Lingkungan. E-Journal Unair. 2015;8(1).
10. Zakiudin A, S Z. Perilaku Kebersihan Diri (Personal Hygiene) Santri di Pondok Pesantren Wilayah Kabupaten Brebes akan Terwujud Jika Didukung dengan Ketersediaan Sarana dan Prasarana. J Promosi Kesehat Indones [Internet]. 2016;11(2). Available from: https://ejournal.undip.ac.id/index.php/jpki/article/vi ew/19004

11. Nawang Wulan DS. Hubungan Antara Peran Kelompok Teman Sebaya (Peer Group) dan Interaksi Siswa dalam Kelompok dengan Kedisiplinan Belajar Siswa Kelas XI MAN 1 Sragen. Eprints UNS [Internet]. 2007; Available from: https://eprints.uns.ac.id

12. Husni. Perbedaan Pengetahuan Dan Sikap Perilaku Hidup Bersih Dan Sehat (PHBS) Antara Santri Putra Dan Santri Putri. J Nurs Stud [Internet]. 2012;1(1):197-204. Available from: https://docplayer-

info.cdn.ampproject.org/v/s/docplayer.info/amp/34 197469-perbedaan

13. Notoadmodjo S. Ilmu Perilaku Kesehatan. Jakarta: Rineka cipta; 2010.

14. Mubarak. Promosi Kesehatan Sebuah Pengamatan Proses Belajar Mengajar dalam Pendidikan. Yogyakarta: Graha Ilmu; 2007.

15. Purwandari R, A Anisah, Wantiyah. Hubungan Antara Perilaku Mencuci Tangan Dengan Insiden Diare Pada Anak Usia Sekolah di Kabupaten Jember. J Keperawatan [Internet]. 2013;4(2). Available from: http://ejournal.umm.ac.id/index.php/keperawatan/ar ticle/view/2362

16. Badri M. Hygiene Perseorangan Santri Pondok Pesantren Wali Songo Ngabar Ponorogo. Media Litbang Kesehatan. E-journal iltbang depkes [Internet]. 2007;17(2):20-7. Available from: http://ejournal.litbang.depkes.go.id/index.php/MPK /article/view/810 